\title{
Enhanced Viscosity of Aqueous Palygorskite Suspensions through Physical and Chemical Processing
}

\author{
Feng-shan Zhou, ${ }^{1}$ Tian-qi Li, ${ }^{1}$ Yun-hua Yan, ${ }^{2}$ Can Cao, ${ }^{1}$ Lin Zhou, ${ }^{1}$ and Yang Liu ${ }^{1}$ \\ ${ }^{1}$ School of Materials Science and Technology, China University of Geosciences (Beijing), Beijing 100083, China \\ ${ }^{2}$ The Key Laboratory of Orogenic Belts and Crustal Evolution, School of Earth and Space Sciences, Peking University, \\ Beijing 100871, China
}

Correspondence should be addressed to Feng-shan Zhou; zhoufs@cugb.edu.cn

Received 12 July 2014; Revised 14 August 2014; Accepted 14 August 2014

Academic Editor: Zhaohui Li

Copyright (C) 2015 Feng-shan Zhou et al. This is an open access article distributed under the Creative Commons Attribution License, which permits unrestricted use, distribution, and reproduction in any medium, provided the original work is properly cited.

\begin{abstract}
Palygorskite has remarkable rheological properties and was used to increase the stability and viscosity of aqueous suspensions. The effects of different physical and chemical processing methods on the apparent viscosity and plastic viscosity of the palygorskite suspensions such as pressing, ultrasound scattering, acidification, and chemical additives have been released. The pressing and ultrasound scattering indicated that the dispersed state of palygorskite could be increased effectively after treatment, and the apparent viscosity of treated-palygorskite samples increased almost 2-3 times compared to that of before. The viscosity of the acid-treated palygorskite suspension was not increased. The viscosity increased with the content of bentonite in the mixture of bentonite and palygorskite in fresh water. It seemed to be not worthy to add a certain amount of bentonite to palygorskite in order to enhance viscosity and vice versa. Chemical additives appeared to have good effects on the rheological behavior of palygorskite suspension. Magnesium oxide revealed great contribution to viscosity enhancement. The main mechanism was the electrostatic attractive interaction between magnesium oxide particles with positive charges and the palygorskite rods with negative charges. This interacted force has an impact on the structural inversion of palygorskite rods and even caused the reinforcing of flocculation.
\end{abstract}

\section{Introduction}

Clay minerals have remarkable rheological properties and are used to increase the stability and viscosity of flowing suspensions. They tend to form gel-like structures at low solid contents [1]. This property is of great importance in a very wide range of applications for drilling fluids, paints, liquid fertilizers, wild-fire suppressants, foundry coatings, animal flowing feeds, molecular sieve binders, and a lot of aqueous suspensions in which rheological properties play a significant role $[1-5]$.

Palygorskite forms gel structures in fresh and salt water by establishing a lattice structure of particles connected through hydrogen bonds. In the drilling industry, these properties enable the clay suspension to suspend the large dense particles of the drilling cuttings and require relatively low pump power during water circulation $[1,7]$. Palygorskite, unlike bentonite, will form gel structures in salt water and is used in special salt-water drilling mud for drilling formations contaminated with salt [8]. Palygorskite particles can be considered as charged particles with zones of positive $(+)$ and negative $(-)$ charges. It is the bonding of these alternating charges that allows them to form gel suspensions in salt and fresh water.

Although most clay minerals form stable and viscous suspensions when dispersed in water, the mechanisms of gel formation for each clay mineral differ because of their unique structures, particle size and shape, and composition $[9,10]$.

Unlike the swelling clay minerals such as montmorillonite, palygorskite as a fibrous nonswelling clay mineral, the fibre length and number of silanol groups on the surface of the fibre play an important role in aggregating fibres together [11] and forming a random network that entraps water and increases viscosity [12].

Neaman and Singer [13-15] systematically studied the rheological properties of six palygorskite samples, used them 
TABLE 1: The chemical compositions, the physical properties, and the theoretical crystal structural formula of the palygorskite sample in present work.

\begin{tabular}{|c|c|c|c|c|c|c|c|c|c|c|c|}
\hline Components & $\mathrm{SiO}_{2}$ & $\mathrm{Al}_{2} \mathrm{O}_{3}$ & $\mathrm{TiO}_{2}$ & $\mathrm{Fe}_{2} \mathrm{O}_{3}$ & $\mathrm{FeO}$ & $\mathrm{MgO}$ & $\mathrm{CaO}$ & $\mathrm{Na}_{2} \mathrm{O}$ & $\mathrm{K}_{2} \mathrm{O}$ & $\mathrm{P}_{2} \mathrm{O}_{5}$ & $\mathrm{SO}_{3}$ \\
\hline Content/wt\% & 64.89 & 12.95 & 1.26 & 8.19 & 0.16 & 9.11 & 1.48 & 0.07 & 1.33 & 0.43 & 0.02 \\
\hline & & Crystal & ctural & $\begin{array}{l}\text { ula: }(\mathrm{Mg} \\
\text { on excha } \\
\text { Spec }\end{array}$ & $\begin{array}{l}\mathrm{l}_{0.73} \mathrm{~F} \\
\text { capac } \\
\text { urfac }\end{array}$ & $\begin{array}{l}\mathrm{Ca}_{0.09} \mathrm{~T} \\
\mathrm{CEC}): 4 \\
\mathrm{a}: 462.0\end{array}$ & $\begin{array}{l}\left(\mathrm{Si}_{3.83}\right. \\
\text { heq } / 10 \\
\mathrm{~g}\end{array}$ & $\mathrm{O}_{10}(\mathrm{O}$ & $\mathrm{H}_{2} \mathrm{O}$ & & \\
\hline
\end{tabular}

as a kind of common thixotropic modifier in aqueous suspensions, and focused on the influence factors including the ratio of crystal length to diameter, concentration of sodium chloride $(\mathrm{NaCl})$, and $\mathrm{pH}$. The effects of pressing modification and adding magnesium oxide (MgO) [16, 17], ultrasound scattering $[18,19]$, acidification $[6,20]$, and even the mixed palygorskite-bentonite suspensions [21] on the rheological properties of palygorskite suspensions also have been studied.

High-pressure homogenization process with solvent and electrolytes with dispersion properties of palygorskite were investigated in detail by $\mathrm{Xu}$ et al. [22-24]. They dispersed the natural palygorskite in six solvents including distilled water, methanol, ethanol, isopropanol, dimethyl formamide, and dimethyl sulfoxide and then carried out high-pressure homogenization. They confirmed that colloidal stability and suspension viscosity were affected by the solvent nature, and a much higher viscosity was obtained by dispersing palygorskite in isopropanol, but the good colloidal stability was obtained in dimethyl sulfoxide (DMSO) solvent. A series of palygorskite samples modified with inorganic potassium electrolytes including $\mathrm{KCl}, \mathrm{KBr}, \mathrm{KI}, \mathrm{KH}_{2} \mathrm{PO}_{4}$, $\mathrm{KHSO}_{4}, \mathrm{~K}_{2} \mathrm{HPO}_{4}, \mathrm{~K}_{2} \mathrm{SO}_{4}$, and $\mathrm{K}_{3} \mathrm{PO}_{4}$ were prepared with the aid of high-pressure homogenization. A stable suspension was obtained when palygorskite was dispersed in $\mathrm{K}_{2} \mathrm{SO}_{4}$ solutions. Because the requirement of the viscosity is more than the stability for palygorskite suspension, obviously, high prices and toxic solvents in their works would be limiting the value of industrial applications.

However, no one had systematically studied the influence of viscosity and the methods of enhanced viscosity for palygorskite gel. The purpose of the present work is to study the effects of different physical and chemical processing methods, such as pressing, ultrasound scattering, acidification, and chemical additives, on the apparent viscosity and plastic viscosity of the aqueous palygorskite suspensions.

\section{Materials and Methods}

2.1. Materials. Palygorskite mineral sample with purity greater than 95\% was received from Mingguang Palygorskite Mining Co., Ltd. (Anhui, China). The average length of the palygorskite rods is around $1 \mu \mathrm{m}$, and the average aspect ratio is about 20 . The chemical compositions, the physical properties, and the theoretical crystal structural formula of the palygorskite sample in present work are listed in Table 1.

There are two bentonite mineral samples used in this work. One bentonite sample was obtained from Sinopec Shengli Oilfield Co., Ltd. (Shandong, China). Another bentonite containing palygorskite sample from Iraq Anbar was obtained from Beijing Taihua Bentonite Science \& Technology Development Co., Ltd. (Beijing, China). Industrial grade magnesium oxide (also named calcined magnesia; light-burned magnesia) ( $\mathrm{MgO}$ ) and magnesium hydroxide $\left(\mathrm{Mg}(\mathrm{OH})_{2}\right)$ samples were obtained from Dandong Yilong High Science \& Technological Materials Co., Ltd. (Liaoning, China).

2.2. Instruments. The experiment of pressing palygorskite was conducted on Jinniu JL-80 vertical grinder $(1.5 \mathrm{KW}$; Hualian Industry Co., Ltd.) (Beijing, China). The ultrasonic dispersion test was carried out by JY92-IIDN ultrasonic cell crusher (20-24 KHz, 650 W; Ningbo Scientz Biotechnology Co., Ltd.) (Zhejiang, China). The modified palygorskite was filtrated by SHB-III water circulation pumps (180 W; Xian Taikang Biotechnology Co., Ltd.) (Shaanxi, China) and dried by a 101-3 electric blast drying oven $\left(300^{\circ} \mathrm{C}\right.$ maximum; Shanghai Rolling-gen Equipment Co., Ltd.) (Shanghai, China). The gelation of samples dispersion was prepared after being stirred by GJ-2S digital display high-speed agitator (180 W, 4000-11000 rpm). The rheological parameters of suspensions were conducted by ZNN-D6A six-speed rotary viscometer (speed: 3, 6, 100, 200, 300, and $600 \mathrm{rpm}$, viscosity range: $0-$ $300 \mathrm{mPa} \cdot \mathrm{s})$. Both of the latter instruments were manufactured by Qingdao Haitongda Special Instrument Co., Ltd. (Shandong, China).

\subsection{Methods}

\subsubsection{Palygorskite Modification}

Pressing. A certain amount of palygorskite and tap-water was mixed and pressed by a vertical extruder. After that, the palygorskite was collected, dried, and ground.

Ultrasound Scattering. 25 g palygorskite and a certain amount of tap-water were added into an $80 \mathrm{~mL}$ beaker, stirred, and then loaded onto the platform of an ultrasonic cell crusher. The time of ultrasound scattering on the platform of ultrasonic cell crusher was $10 \mathrm{~min}$ and repeated 2-3 times to make a better dispersion.

Acidification. The clay mineral was treated with hydrochloric acid at a concentration of $2 \mathrm{~mol} / \mathrm{L}$ by liquid and a solid ratio of 10 to 1 in the flask, under mechanical stirring $(550 \mathrm{rpm})$ in dispersion at room temperature for $1 \mathrm{~h}$. Then the sample was filtrated, followed by washing with distilled water until a $\mathrm{pH}$ value 3-4 was reached. 
TABLE 2: The effect of pressing on the rheological parameters of palygorskite suspension.

\begin{tabular}{lcccccc}
\hline Samples of palygorskite & \multicolumn{5}{c}{ Rheological parameters } \\
& $\begin{array}{c}\theta_{600} \\
(\text { dia })\end{array}$ & $\begin{array}{c}\theta_{300} \\
(\text { dia })\end{array}$ & $\begin{array}{c}\text { AV } \\
(\mathrm{mPa} \cdot \mathrm{s})\end{array}$ & $\begin{array}{c}\mathrm{PV} \\
(\mathrm{mPa} \cdot \mathrm{s})\end{array}$ & $\begin{array}{c}\text { YP } \\
(\mathrm{Pa})\end{array}$ & $\begin{array}{c}\text { YP/PV } \\
(\mathrm{Pa} / \mathrm{mPa} \cdot \mathrm{s})\end{array}$ \\
\hline Unpressing & 39 & 35 & 19.5 & 4.0 & 15.84 & 3.96 \\
Unpressing with $1 \% \mathrm{MgO}$ & 59 & 44 & 29.5 & 15.0 & 14.82 & 2.00 \\
Pressing without $\mathrm{MgO}$ & 48 & 41 & 24.0 & 7.0 & 17.37 & 3.48 \\
Pressing with $1 \% \mathrm{MgO}$ & 85 & 75 & 42.5 & & 3.22 \\
\hline
\end{tabular}

Chemical Additives. Certain amounts of additives were added into $6.4 \mathrm{w} / \mathrm{v} \%$ palygorskite dispersions. The dosage of chemical additives (\%) in the tables and the figures was the ratio of mass between chemicals and palygorskite.

The dispersions were stirred mechanically at $8000 \mathrm{rpm}$ for $20 \mathrm{~min}$ at room temperature and hydration was conducted for $24 \mathrm{~h}$. The term of hydration was an ageing process of water penetrating the interlayer spaces and concomitant adsorption with the clay swelling and colloidization.

2.3.2. Rheological Parameters Measurement. Darley and George [8] concluded the common composition and properties of drilling and completion fluids. According to the American Petroleum Institute (API) recommended practice (2009) [25], the parameters of the palygorskite gel in the drilling fluid suspension samples were prepared and measured under the specification and standard procedures. The viscosity and gel strength of the modified gels were tested by a rotating viscometer $\left(\mathrm{ZNN}_{-} \mathrm{D}_{6} \mathrm{~S}\right)$. The hydrated gels underwent mechanical stirring at $8000 \mathrm{rpm}$ for a further $20 \mathrm{~min}$. This preparation step before measuring the viscosity was to make the dispersion even and flowing. And then the viscosity was measured at different shear rates (different stirring velocity).

2.3.3. Rheological Theory. According to Bingham-plastic model, the rheological parameters, including AV (apparent viscosity), PV (plastic viscosity), YP (yield point), and RYP (ratio of yield and plastic viscosity), were calculated with the dial readings of $300 \mathrm{rpm}$ and $600 \mathrm{rpm}$ using the following formulas according to the API recommended practice of standard procedures [25]:

$$
\begin{gathered}
\mathrm{AV}=0.5 \theta_{600}(\mathrm{mPa} \cdot \mathrm{s}) \\
\mathrm{PV}=\theta_{600}-\theta_{300}(\mathrm{mPa} \cdot \mathrm{s}) \\
\mathrm{YP}=0.511\left(\theta_{300}-\mathrm{PV}\right)(\mathrm{Pa}) \\
\mathrm{RYP}=\frac{\mathrm{YP}}{\mathrm{PV}}(\mathrm{Pa} / \mathrm{mPa} \cdot \mathrm{s})
\end{gathered}
$$

where $\theta_{600}$ (dia) was the dial reading of rotating viscometer at $600 \mathrm{rpm}$ and $\theta_{300}$ (dia) was the dial reading of rotating viscometer at $300 \mathrm{rpm}$.

2.3.4. Microscopic Examination. The morphology of the palygorskite and modified palygorskite with additives was

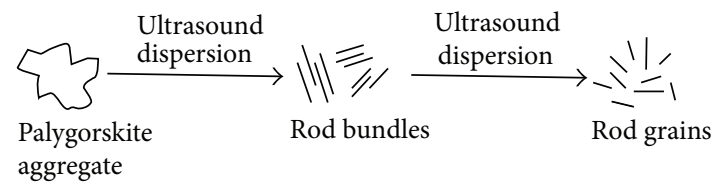

FIGURE 1: The mechanism of ultrasound scattering dispersion for palygorskite aggregates.

observed in a Quanta 200FEG environmental scanning electron microscope (SEM). All of the raw minerals were firstly made to powder samples, which were dried from dilute $0.2 \%$ dispersions before the SEM examination. The modified palygorskite gel samples were also dried out from the same concentration before SEM measurement.

\section{Results and Discussion}

3.1. Pressing Effect. Pressing as an effective way to break up close and compact bulks of natural palygorskite rods could more easily disperse palygorskite fibers in water. Experimental measurement of viscosity of pressed palygorskite showed that the apparent viscosity increased from $19.5 \mathrm{mPa} \cdot \mathrm{s}$ to $42.5 \mathrm{mPa} \cdot \mathrm{s}$ (Table 2).

Pressing can be applied as a useful approach to enhance better dispersion of palygorskite particles, especially for raw palygorskite aggregates. However, in our opinion, compared to effective viscosity enlarging by using small amount of chemical, the pressing with the inefficient and high cost was not a suitable technique for enhanced viscosity of palygorskite suspension in some applications with low added value such as drilling fluids.

3.2. Ultrasound Scattering Effect. Song et al. [18] found that after treatment with ultrasound the palygorskite crystal bundles were crushed into crystal needles, generating palygorskite nanoparticles. What is more, Zhao et al. [19] studied the dispersion of palygorskite in a polypropylene matrix, and their SEM and TEM analysis results showed that ultrasonic oscillation promoted the dispersion of palygorskite particles (Figure 1).

Under the condition of ultrasound dispersion, the apparent viscosity was raised rapidly from $19.5 \mathrm{mPa} \cdot \mathrm{s}$ to $54 \mathrm{mPa} \cdot \mathrm{s}$ (Table 3). The enhancement of viscosity was related to the fact that ultrasonic cavitation could cause local high temperature and high pressure. The shock wave and microjet in dispersion brought about intense collisions of palygorskite aggregates 
TABLE 3: The effect of ultrasound scattering on the rheological parameters of palygorskite suspension.

\begin{tabular}{|c|c|c|c|c|c|c|}
\hline \multirow[b]{2}{*}{ Samples of palygorskite } & \multicolumn{6}{|c|}{ Rheological parameters } \\
\hline & $\begin{array}{l}\theta_{600} \\
\text { (dia) }\end{array}$ & $\begin{array}{l}\theta_{300} \\
\text { (dia) }\end{array}$ & $\begin{array}{c}\mathrm{AV} \\
(\mathrm{mPa} \cdot \mathrm{s})\end{array}$ & $\begin{array}{c}\mathrm{PV} \\
(\mathrm{mPa} \cdot \mathrm{s})\end{array}$ & $\begin{array}{l}\text { YP } \\
(\mathrm{Pa})\end{array}$ & $\begin{array}{c}\mathrm{YP} / \mathrm{PV} \\
(\mathrm{Pa} / \mathrm{mPa} \cdot \mathrm{s})\end{array}$ \\
\hline No ultrasound scattering & 39 & 35 & 19.5 & 4 & 15.84 & 3.96 \\
\hline Ultrasound scattering & 108 & 92 & 54.0 & 16 & 38.84 & 2.43 \\
\hline
\end{tabular}

in aqueous suspensions just like the same dispersion mechanism in polypropylene matrix described in Figure 1.

3.3. Acidification Effect. Many practices using acid to purify palygorskite have been reported in the literature. For example, Neaman and Singer [20] used acid to remove carbonates and other cement impurities. Other researchers used acidification to break up the cluster of closely bound fibers to increase specific surface area for good dispersion and absorption. The raw material in the experiment was of high purity. Octahedral cations dissolved and crystal structure was even changed because of the high concentration of acid and reaction time. Chen et al. [6] investigated the structural changes of palygorskite with reaction to acid; their results indicated that dissolution of octahedral reactions increased with an increase in acid concentration and reaction time. When octahedral cations were dissolved completely, the final product was mesoporous amorphous silica-fiber (Figure 2).

The study showed that the gel of the acidified palygorskite in dispersion came to serious sedimentation after hydration. Initially, with the ratio of acid to palygorskite being 10 to 1 and concentration of $\mathrm{HCl}$ being $2 \mathrm{~mol} / \mathrm{L}$, the apparent viscosity value was only $5 \mathrm{mPa} \cdot s$. By reducing the concentration and amount of acid solution (weight ratio of acid to palygorskite was 4 to 1 ; concentration of $\mathrm{HCl}$ was $1 \mathrm{~mol} / \mathrm{L}$ ), the $\mathrm{AV}$ still measured only $10 \mathrm{mPa} \cdot \mathrm{s}$. Obviously, acidizing palygorskite viscosity was not enhanced in the present work; the opposite is the case.

3.4. Effects of Bentonite. Several studies have been carried out in the past to understand the rheological properties of standard clays $[9,10,13-15,26-28]$. However, there are a lot of works on the rheological properties of mixed clay suspensions in recent years. The influence of montmorillonite addition on the rheological behaviour of palygorskite suspensions was investigated by Neaman and Singer [13-15]. Rheological properties of palygorskite-bentonite mixed clay suspensions were studied by Chemeda et al. [21].

The limited information is considered important because most clay used such as in drilling fluid applications usually contains more than one type of clay minerals along with nonclay minerals. For example, palygorskite occurs in association with smectite in most of the known world palygorskite deposits [6]. Therefore it is worthwhile to understand the rheological behavior of suspensions containing mixtures of clay minerals.

The most difference of rheological properties between palygorskite and bentonite was that palygorskite can be used in fresh water and salt water, but the bentonite is only used in fresh water. Figure 3 shows the effects of bentonite addition on the viscosity of bentonite-palygorskite mixture. The viscosity of the mixture increased with the increase of content of bentonite in mixture in fresh water. But the viscosity of the mixture decreased with the increase of content of bentonite in mixture in salt water because of the poor salt tolerance of bentonite. Taking into account the effect, nature, and the price ratio, it was not worthy to add a certain amount of bentonite to palygorskite, because the palygorskite is normally used in salt water condition. For the same reason, it was also worthless to add a certain amount of palygorskite to bentonite.

In contrast to the admixture of bentonite and palygorskite, some kinds of natural coexisting bentonitepalygorskite clay mixture would have a very high viscosity (Figure 4), because their random network structures were formed more easily which entrapped water and increased viscosity. But for some others, the same viscosity behavior does not appear [6]; the real reason is still unknown.

3.5. Effects of Magnesium Oxide. The experimental measurements of samples with chemical additives (Figure 5) exhibited that the sample added $\mathrm{MgO}$ showed an increased viscosity value with lower $\mathrm{MgO}$ content. This higher viscosity value exhibited better cuttings suspension and carrying capacity in drilling fluids.

When $\mathrm{MgO}$ particles were added to water, the reaction happened as follows:

$$
\mathrm{MgO}+\mathrm{H}_{2} \mathrm{O} \rightleftharpoons \mathrm{Mg}(\mathrm{OH})_{2} \rightleftharpoons \mathrm{Mg}^{2+}+2 \mathrm{OH}^{-}
$$

The cation exchange ability of $\mathrm{Mg}^{2+}$ was better than $\mathrm{Na}^{+}$. The $\mathrm{Mg}^{2+}$ entered into the channels of clay mineral particles and caused shrinkage of the electrical double layer. The shrinkage of the electrical double layer easily formed face-face aggregation. At the same time, the absorbed $\mathrm{Mg}^{2+}$ bridged edge and face formed edge-edge and edge-face flocculation.

As already stated above, the PV reflected the internal friction of suspended particles, the liquid phase, and their interface. Flocculation reinforced the suspension network structure with expression of an increase on viscosity.

SEM micrographs of the palygorskite with $\mathrm{Mg}(\mathrm{OH})_{2}$ and $\mathrm{MgO}$ (Figure 6) revealed that the palygorskite had a fibrous morphology and that $\mathrm{Mg}(\mathrm{OH})_{2}$ and $\mathrm{MgO}$ particles with positive charge dispersed in the palygorskite scaffolding structure with negative charge. The electrostatic attractive interaction also reinforced the palygorskite structure, confirming the increase in viscosity. 


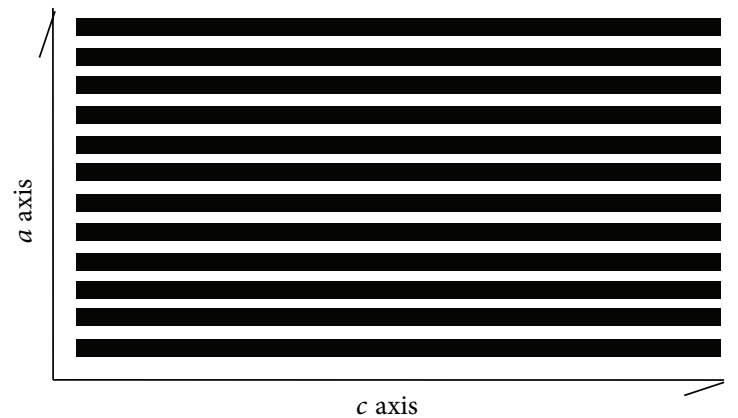

(a)

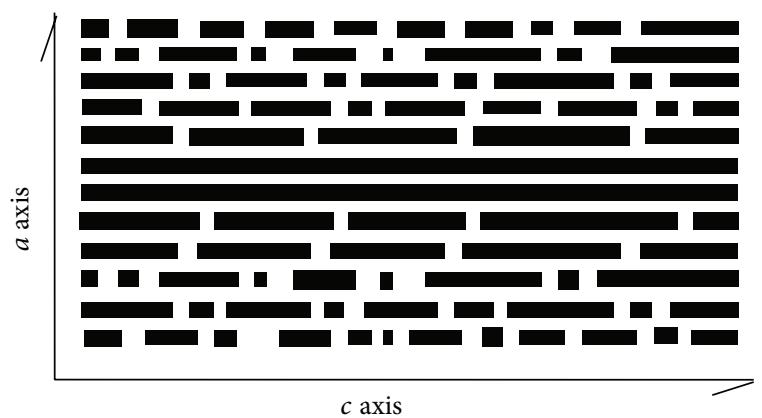

(b)

FIGURE 2: The channel structure change of palygorskite with acidification treatment [6]. (a) The original channel structure of palygorskite.

(b) The channel structure of palygorskite after acidification with hydrochloric acid.

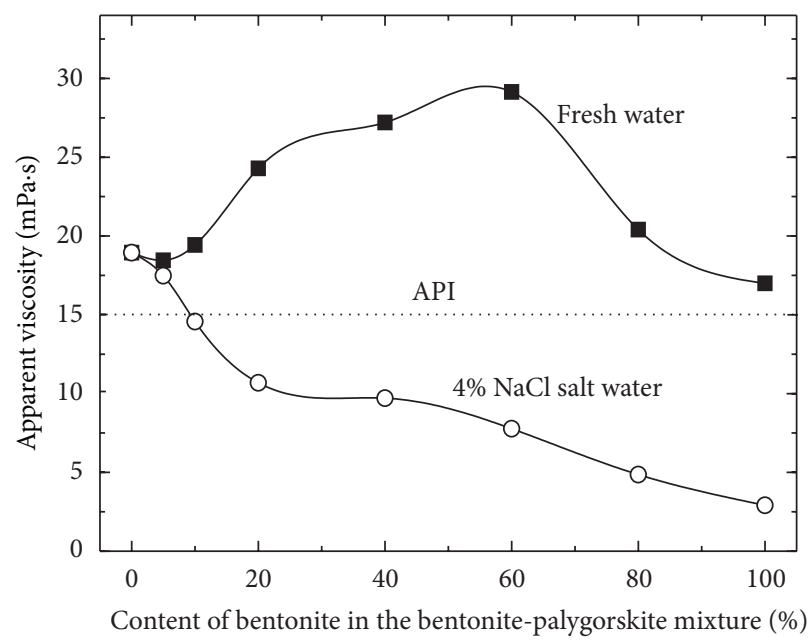

FIGURE 3: The effects of bentonite addition on the viscosity of suspension of bentonite-palygorskite mixture in fresh water and salt water.

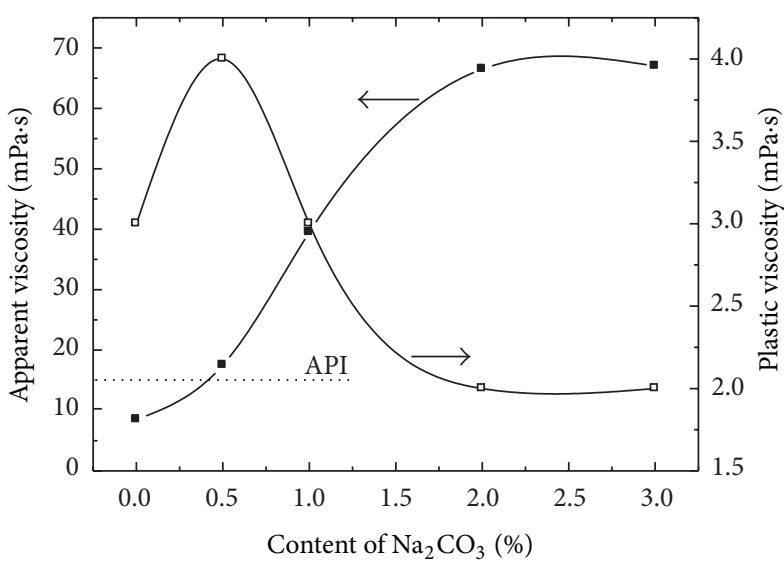

(a)

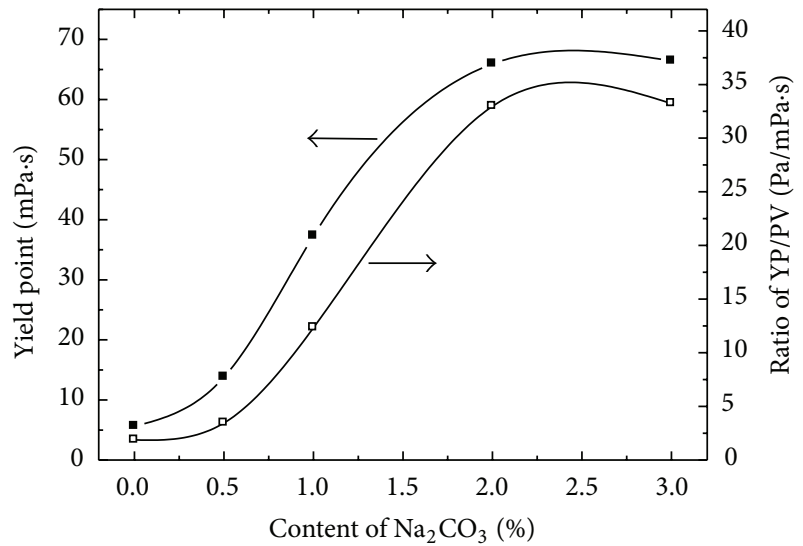

(b)

FIGURE 4: The viscosity of a natural coexisting clay mixture sample with $7 \%$ palygorskite and $57 \%$ sodium-calcium based hybrid bentonite from Iraq Anbar. (a) The apparent viscosity and plastic viscosity of the natural coexisting clay mixture. (b) The yield point and ratio of YP/PV of the natural coexisting clay mixture. 


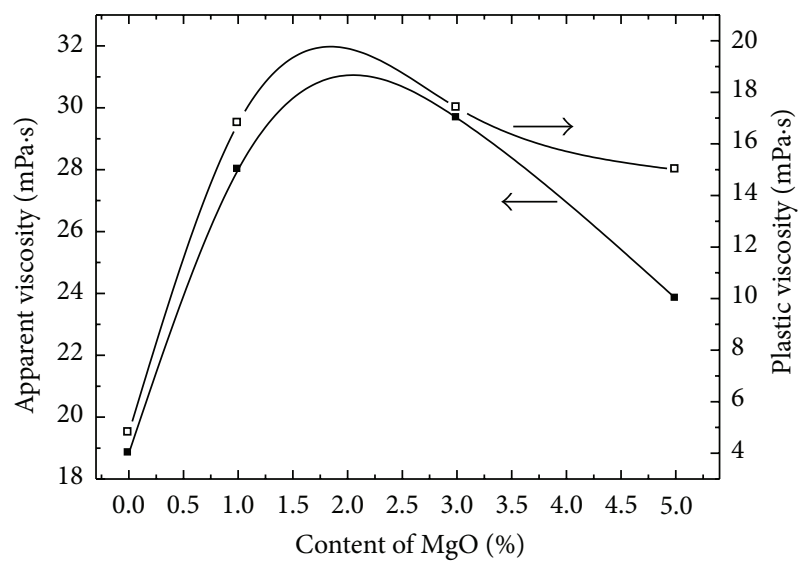

(a)

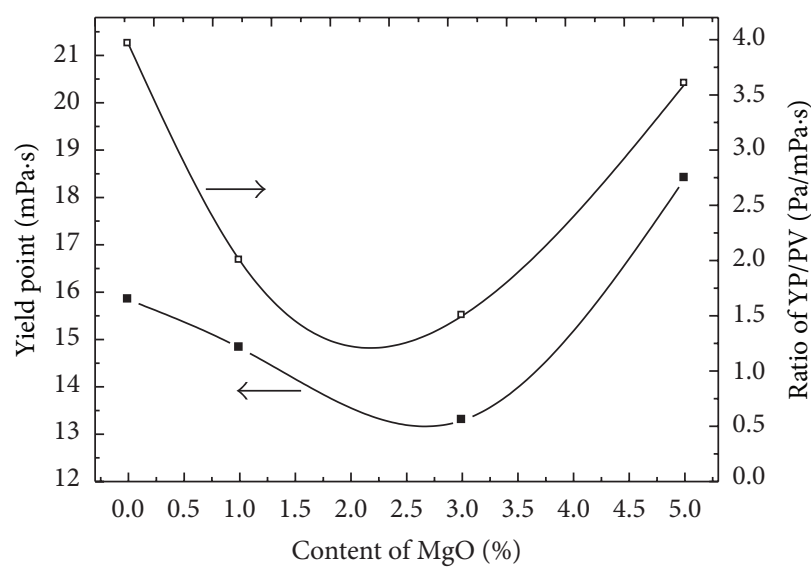

(b)

FIGURE 5: The effects of MgO on the rheological parameters of palygorskite suspension. (a) The apparent viscosity and plastic viscosity of palygorskite suspension. (b) The yield point and ratio of YP/PV of palygorskite suspension.

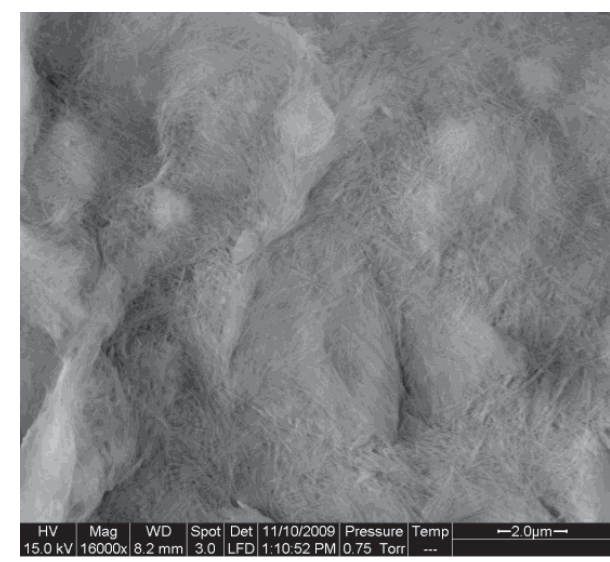

(a)

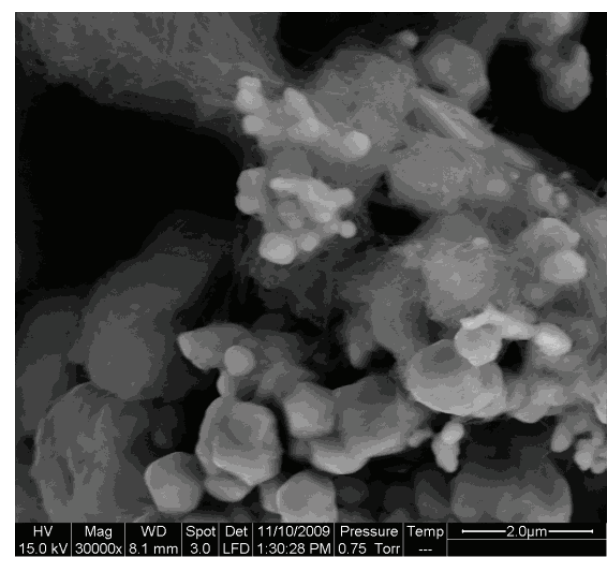

(b)

FIGURE 6: The change of scanning electron microscope photograph of palygorskite processed with magnesium oxide. (a) SEM micrograph of original unmodified palygorskite. (b) SEM micrograph of palygorskite modified adding MgO.

\section{Conclusions}

The results of the pressing and ultrasound scattering effect studies indicated that the dispersed state and increasing viscosity of clay mineral gel could be adjusted by the two methods effectively. The mechanisms were that pressing broke up close and compact palygorskite rods clusters, and ultrasonic cavitations caused intense collisions within the palygorskite aggregate. Consequently, pressing and ultrasound scattering could be used as useful modification methods for improving the viscosity of the aqueous suspension of palygorskite.

The acidification effect would not increase the viscosity of palygorskite, perhaps because the high concentration acidification was harmful for gelation and dispersion of palygorskite.

The viscosity of the mixture of bentonite and palygorskite increased with the increase of content of bentonite in fresh water. But the viscosity of the mixture decreased with the increase of content of bentonite in salt water because of the poor salt tolerance of bentonite. It seemed to be not worthy to add a certain amount of bentonite to palygorskite in order to enhance viscosity.

Chemical additives showed good effects on the rheological and thixotropic behavior of palygorskite suspension. The results of adding $\mathrm{MgO}$ revealed that the contribution of $\mathrm{MgO}$ to viscosity caused the reinforcing of flocculation. Furthermore, the analysis showed that electrostatic attractive interaction between $\mathrm{MgO}$ particles dispersed in the scaffolding structure with positive charges and the palygorskite rods with negative charges had impact on the inversion of palygorskite rods configuration. In drilling applications, this higher viscosity value will provide better cuttings suspension and carrying capacity.

\section{Conflict of Interests}

The authors declare that there is no conflict of interests regarding the publication of this paper. 


\section{Acknowledgment}

Thanks are due to Dr. Susan Turner (Brisbane) for the helpful comments on the paper and for improving the English language.

\section{References}

[1] P. F. Luckham and S. Rossi, "The colloidal and rheological properties of bentonite suspensions," Advances in Colloid and Interface Science, vol. 82, no. 1-3, pp. 43-92, 1999.

[2] N. P. Chafe and J. R. de Bruyn, "Drag and relaxation in a bentonite clay suspension," Journal of Non-Newtonian Fluid Mechanics, vol. 131, no. 1-3, pp. 44-52, 2005.

[3] E. Galan, "Properties and applications of palygorskite-sepiolite clays," Clay Minerals, vol. 31, no. 4, pp. 443-453, 1996.

[4] E. Galan and A. Singer, Developments in Palygorskite-Sepiolite Research, A New Outlook on these Nanomaterials, vol. 3 of Developments in Clay Science, Elsevier, New York, NY, USA, 2011.

[5] H. H. Murray, "Occurrences, processing and application of kaolins, bentonites, palygorskite-sepiolite, and common clays," in Developments in Clay Science, vol. 2 of Applied Clay Mineralogy, Elsevier, 2007.

[6] T. H. Chen, Y. L. Feng, and X. Shi, "Study on products and structural changes of reaction of palygorskite with acid," Journal of the Chinese Ceramic Society, vol. 31, no. 10, pp. 959-964, 2004.

[7] V. C. Kelessidis, C. Tsamantaki, and P. Dalamarinis, "Effect of $\mathrm{pH}$ and electrolyte on the rheology of aqueous Wyoming bentonite dispersions," Applied Clay Science, vol. 38, no. 1-2, pp. 86-96, 2007.

[8] H. C. H. Darley and R. G. George, Composition and Properties of Drilling and Completion Fluids, Gulf Professional, Houston, Tex, USA, 6th edition, 2011.

[9] H. Heller and R. Keren, "Rheology of Na-rich montmorillonite suspension as affected by electrolyte concentration and shear rate," Clays and Clay Minerals, vol. 49, no. 4, pp. 286-291, 2001.

[10] E. Paineau, L. J. Michot, I. Bihannic, and C. Baravian, "Aqueous suspensions of natural swelling clay minerals. 2. Rheological characterization," Langmuir, vol. 27, no. 12, pp. 7806-7819, 2011.

[11] T. C. Simonton, S. Komarneni, and R. Roy, "Gelling properties of sepiolite versus montmorillonite," Applied Clay Science, vol. 3, no. 2, pp. 165-176, 1988.

[12] G. E. Christidis, P. Katsiki, A. Pratikakis, and G. Kacandes, "Rheological properties of palygorskite-smectite suspensions from the Ventzia basin, W. Macedonia, Greece," Bulletin of the Geological Society of Greece, vol. 43, pp. 2562-2569, 2011.

[13] A. Neaman and A. Singer, "Kinetics of hydrolysis of some palygotskite-containing soil clays in dilute salt solutions," Clays and Clay Minerals, vol. 48, no. 6, pp. 708-712, 2000.

[14] A. Neaman and A. Singer, "Rheology of mixed palygorskitemontmorillonite suspensions," Clays and Clay Minerals, vol. 48, no. 6, pp. 713-715, 2000.

[15] A. Neaman and A. Singer, "Rheological properties of aqueous suspensions of palygorskite," Soil Science Society of America Journal, vol. 64, no. 1, pp. 427-436, 2000.

[16] J. Zhou, L. J. Liu, N. Liu, and X. F. Liu, "Effects of $\mathrm{Mg}(\mathrm{OH})_{2}$ and $\mathrm{MgO}$ on rheological behavior of attapulgite clay-water suspensions," Journal of Hefei University of Technology, no. 6, pp. 58-63, 1999.
[17] J. Zhou, N. Liu, Y. Li, and Y. J. Ma, "Microscopic structure characteristics of attapulgite," Bulletin of the Chinese Ceramic Society, vol. 18, no. 6, pp. 50-55, 1999.

[18] R. F. Song, L. Y. Yang, J. Sheng, N. X. Shen, and T. W. Kang, "The surface modification and characterization of nano-attapulgite," Bulletin of the Chinese Ceramic Society, vol. 22, no. 3, pp. 36-39, 2003.

[19] L. Zhao, Q. Du, G. Jiang, and S. Guo, "Attapulgite and ultrasonic oscillation induced crystallization behavior of polypropylene," Journal of Polymer Science B: Polymer Physics, vol. 45, no. 16, pp. 2300-2308, 2007.

[20] A. Neaman and A. Singer, "Possible use of the Sacalum (Yucatan) palygorskite as drilling muds," Applied Clay Science, vol. 25, no. 1-2, pp. 121-124, 2004.

[21] Y. C. Chemeda, G. E. Christidis, N. M. Tauhid-Khan, E. Koutsopoulou, V. Hatzistamou, and V. Kelessidis, "Rheological properties of palygorskite-bentonite and sepiolite-bentonite mixed clay suspensions," Applied Clay Science, vol. 90, pp. 165174, 2000.

[22] J. Xu, W. Wang, and A. Wang, "Effects of solvent treatment and high-pressure homogenization process on dispersion properties of palygorskite," Powder Technology, vol. 235, pp. 652-660, 2013.

[23] J. Xu, W. Wang, and A. Wang, "Superior dispersion properties of palygorskite in dimethyl sulfoxide via high-pressure homogenization process," Applied Clay Science, vol. 86, pp. 174-178, 2013.

[24] J. Xu, W. Wang, and A. Wang, "Influence of anions on the electrokinetic and colloidal properties of palygorskite clay via high-pressure homogenization," Journal of Chemical and Engineering Data, vol. 58, no. 3, pp. 764-772, 2013.

[25] ANSI/API Recommended Practice 13B-1, Recommended Practice for Field Testing Water-Based Drilling Fluids, American Petroleum Institute, 4th edition, 2009.

[26] S. Abend and G. Lagaly, "Sol-gel transitions of sodium montmorillonite dispersions," Applied Clay Science, vol. 16, no. 3-4, pp. 201-227, 2000.

[27] L. V. Amorim, C. M. Gomes, H. L. Lira, K. B. Franca, and H. C. Ferreira, "Bentonites from Boa Vista, Brazil: physical, mineralogical and rheological properties," Materials Research, vol. 7, no. 4, pp. 583-593, 2004.

[28] G. E. Christidis, A. E. Blum, and D. D. Eberl, "Influence of layer charge and charge distribution of smectites on the flow behaviour and swelling of bentonites," Applied Clay Science, vol. 34, no. 1-4, pp. 125-138, 2006. 

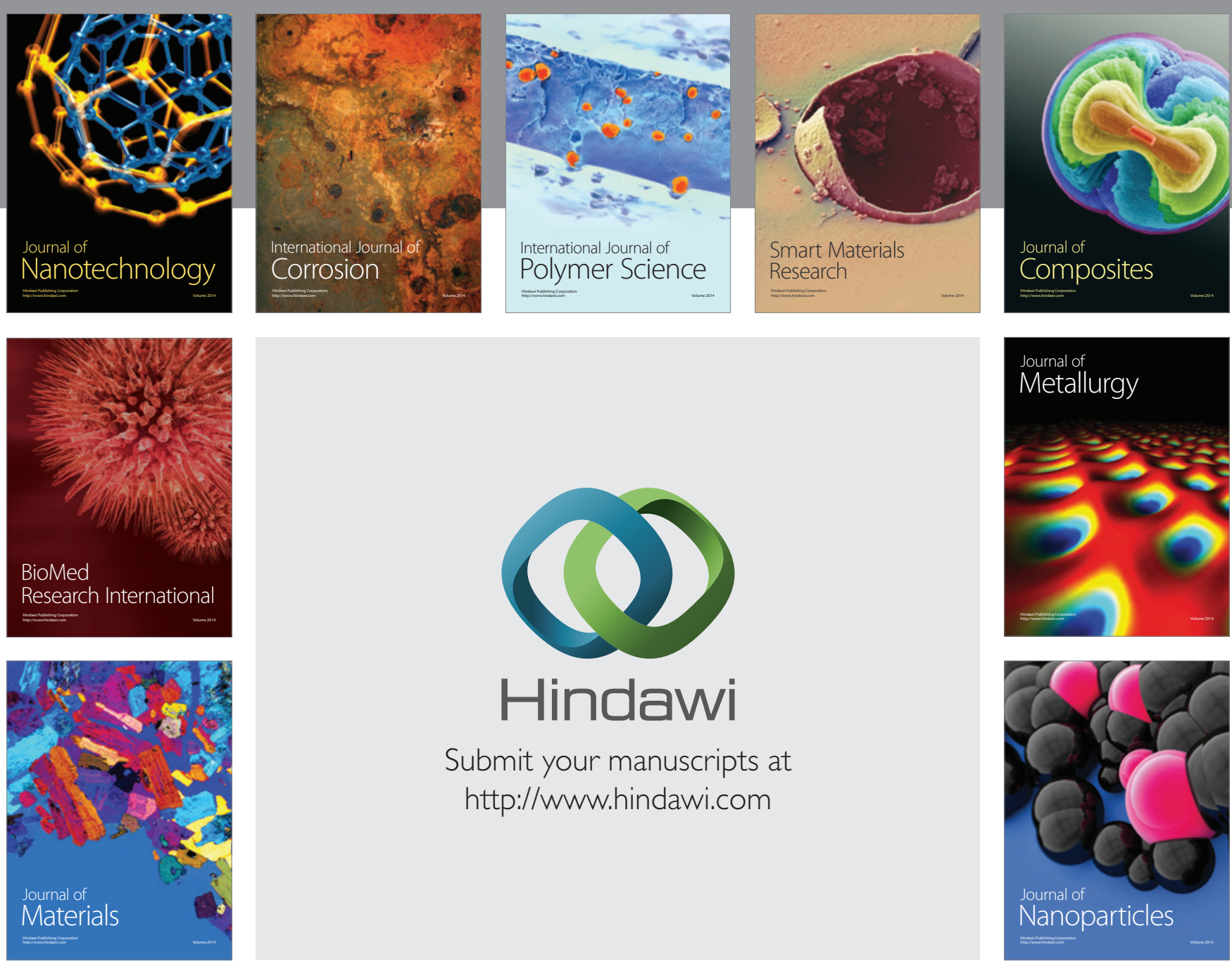

Submit your manuscripts at http://www.hindawi.com
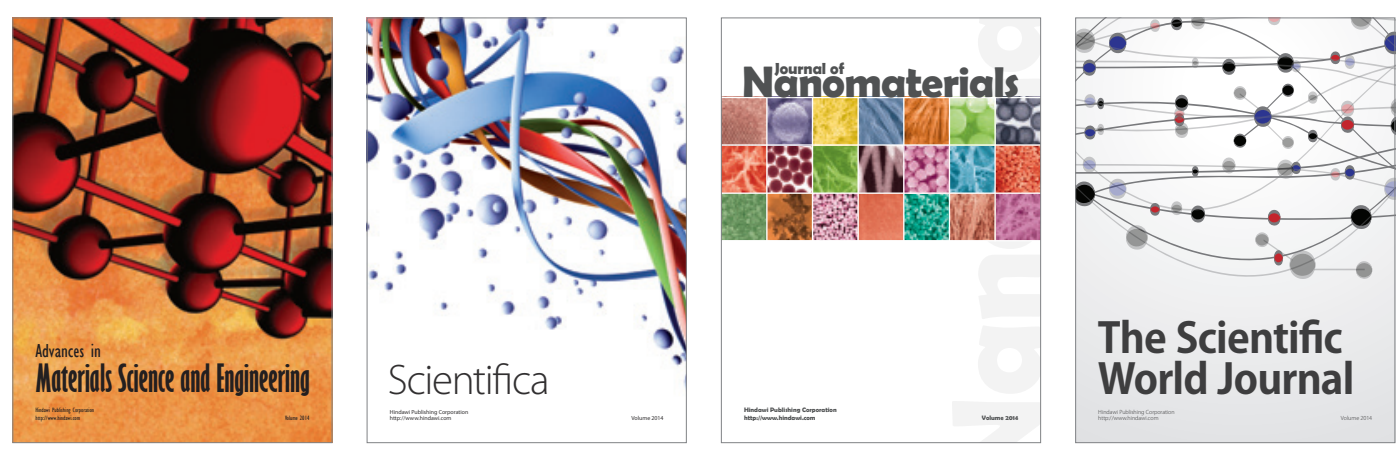

\section{The Scientific World Journal}
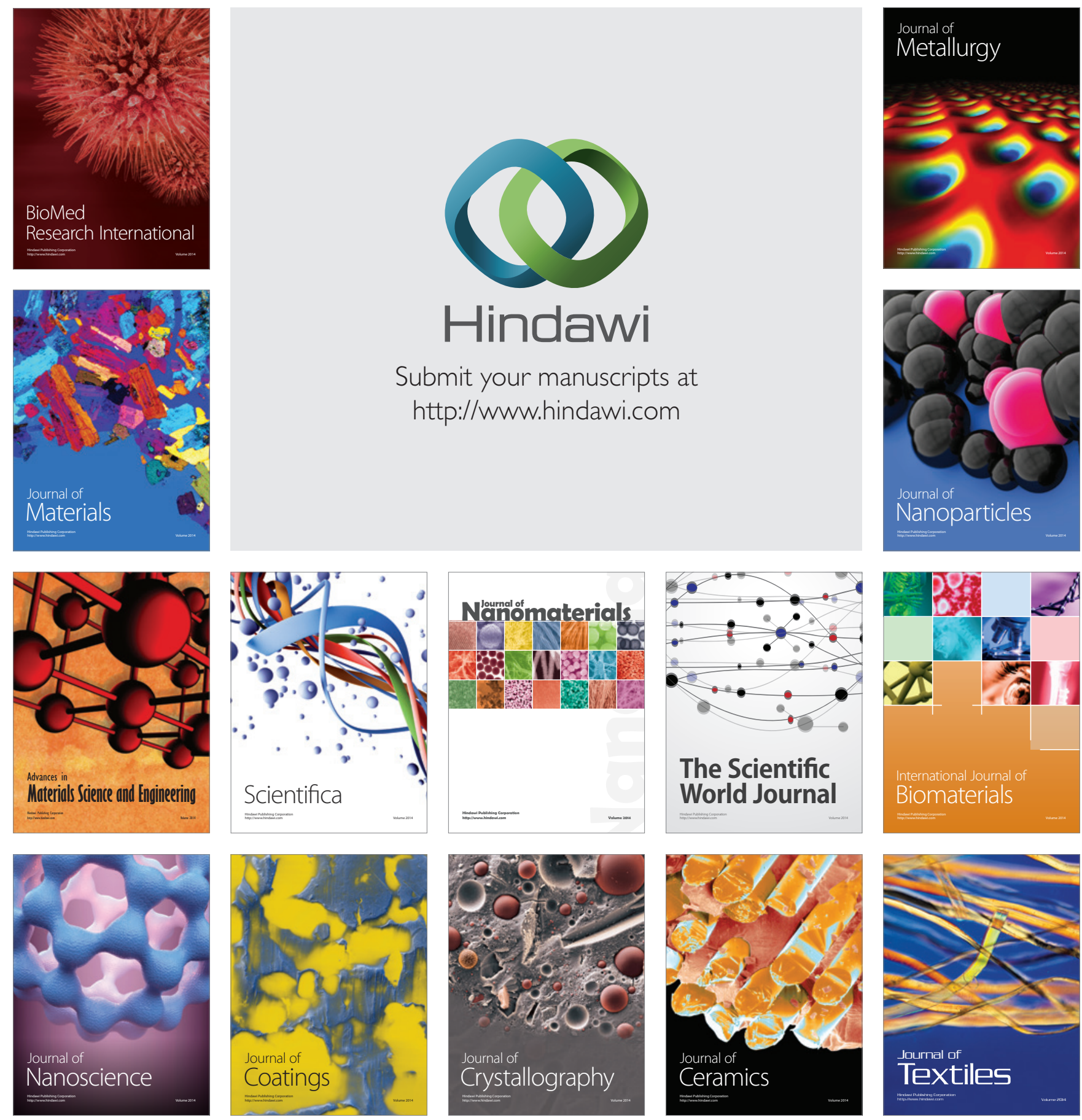